\title{
Pragmatic Failure in Interpretation and the Development of Students' Pragmatic Competence in Interpreting
}

\author{
Licheng $\mathrm{Lu}^{1}$ \\ ${ }^{1}$ Faculty of English Language and Culture, Guangdong University of Foreign Studies, Guangzhou, China \\ Correspondence: Licheng Lu, Faculty of English Language and Culture, Guangdong University of Foreign \\ Studies, No. 2 Baiyun Dadao Bei, Guangzhou, China
}

Received: December 25, 2018

Accepted: January 20, 2019 Online Published: January 22, 2019

doi: $10.5539 /$ elt.v12n3p37

URL: https://doi.org/10.5539/elt.v12n3p37

\begin{abstract}
Based on Jenny Thomas's dichotomous classification of pragmatic failure, this study proposes a new perspective and classifies pragmatic failure in interpretation into three categories: pragma-linguistic failure, socio-pragmatic failure and malaprop-pragmatic failure. Specific examples are given to illustrate the causes and effects of each category of pragmatic failure in interpretation. Meanwhile, this study establishes the "curriculum-textbook-teacher-teaching" scheme to develop students' pragmatic competence in interpreting with which they are able to avoid pragmatic failure in interpretation.
\end{abstract}

Keywords: pragmatic failure, classification, interpretation, pragmatic competence

\section{Introduction}

Interpretation is an act of verbal communication in which information is conveyed from one language into another (Pöchhacker, 2016). It is indispensible to the communications and exchanges between people who speak different languages. As globalization accelerates and countries have closer contacts with one another, interpretation plays a more important role and the need of good interpreters is growing faster than ever.

Under such circumstances, colleges and universities either offer interpretation courses for language majors or even establish interpretation programs. Traditionally, language proficiency and interpretation skills are the foci of interpretation education. They are also the main themes for interpretation research. Yet the fact is that these two qualities alone do not guarantee the success of an interpretation task. Very often a task fails simply because of the interpreter's lack of pragmatic competence. The interpretation, as a result, is grammatically correct and semantically complete but is pragmatically inappropriate. The British linguist Jenny Thomas referred to the pragmatic inappropriateness as "pragmatic failure" (Thomas, 1983). Pragmatic failures are common in interpretation, but little attention has been given to the study of them. How many categories of pragmatic failures are there in interpretation? What are the causes and effects of each category of pragmatic failures? What can be done to avoid them? To answer these questions, the present study examines pragmatic failures in interpretation with specific examples and proposes corresponding strategies to develop students' pragmatic competence in interpreting.

\section{Pragmatic Failure: A Trident Classification Model}

Pragmatic failure refers to "the inability to understand what is meant by what is said (Thomas, 1983, p. 91). In Thomas's research model, it was classified into two types: pragma-linguistic failure and socio-pragmatic failure, with the former referring to the failures caused by mistaken beliefs about pragmatic force of utterance, and the latter to the ones caused by different beliefs about rights, mentionables, etc. Thomas's dichotomous classification of pragmatic failures has been widely studied and cited in later researches. One major subject for research is pragmatic failures in different fields of language use. Setton (1999) illustrated the role of pragmatic competence in simultaneous interpretation and claimed that the cause of communication breakdowns and errors lies in a failure to capture and/or render the pragmatic meanings. Wang (2002) followed Thomas's dichotomous classification and illustrated various reasons for both pragma-linguistic failures and socio-pragmatic failures in interpretation. Hao (2000) studied pragmatic failures in hybrid advertising language. He attempted to redefine and ameliorate the theory of cross-cultural pragmatic failure but was still confined within Thomas's dichotomous classification. Other research subjects include pragmatic failures in second language acquisition (Ellis, 1992; 
Economidou-Kogetsidis, 2011; Cruz, 2013) and causes and effects of pragmatic failures (Sun \& Dai, 2002; Wang, 2007). However, there are also a small number of scholars who called for critical examinations of Thomas's dichotomous classification (Liu \& Zhong, 2003; Liu, 2008). For example, Liu (2008) claimed that Thomas's dichotomous classification is too vague in that it excludes pragmatic failures caused by slip of tongue, language errors and non-verbal failures.

Under the guidance of the critical examinations made on Thomas's dichotomous classification, the present study proposes a trident classification model to examine pragmatic failures in interpretation (See Chart 1).

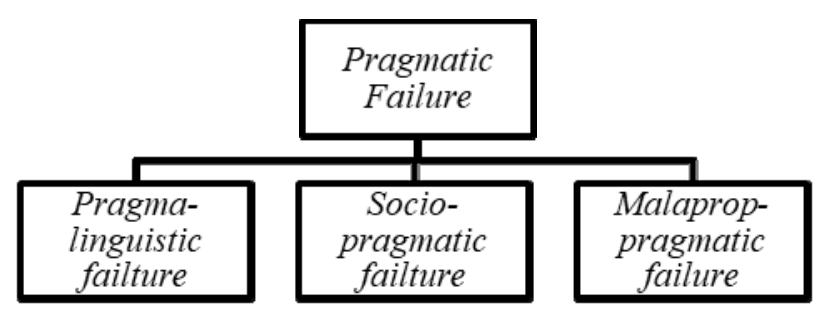

Chart 1. Pragmatic failure: A trident classification model

Compared with Thomas's research findings, this study has identified a number of pragmatic failures in interpretation that do not fit into pragma-linguistic failure or socio-pragmatic failure, for they are caused not by the neglect of linguistic or cultural differences but by the interpreters' slip of tongue, which is why they are put into a third category: malaprop-pragmatic failure.

\section{Pragmatic Failure in Interpretation}

Pragmatic failures abound in interpretation. According to the trident classification model proposed above, they come in three categories: pragma-linguistic failure, socio-pragmatic failure and malaprop-pragmatic failure.

\subsection{Pragma-linguistic Failure in Interpretation}

Chinese and English differ in many aspects, such as vocabulary, structure, style, etc. Thus, pragma-linguistic failures in interpretation appear if an interpreter fails to grasp the fine shades of differences between the two languages. Specific causes and effects of pragma-linguistic failures in interpretation are identified as follows:

\subsubsection{Word-for-Word Interpretation}

(1)

English: Will the goods be shipped to our country by the end of this month?

Chinese: 当然。

Interpreter: Of course.

When answering questions, Chinese people like to use “当然” to show their certainty or determination. However, the English expression "Of course" implies that the answer to the question asked is an obvious one and that it is a little stupid to ask such a question. Such an implication may give the listener an impression that the speaker is rude. Therefore, it's better to use "Yes, certainly." here. Look at another example:

(2)

Chinese: 我们要进一步简化手续, 及时地积极地从国外引进技术, 并且认真组织广大职工做好消化和推 广工作。

Interpreter: We should further simplify procedures and take prompt and vigorous action to import advanced technologies, and then earnestly organize the mass of workers to assimilate and popularize them.

The Chinese language is characteristic of the use of multiple modifiers. When interpreting them into English, interpreters do not need to render all of them word-for-word, otherwise the English version would become too heavy and less spontaneous. In Example (2), all the modifiers have been rendered word-for-word into English, yet this "faithfulness" to the source text has caused unnecessary repetitions in the target text. Therefore, Example (2) should be interpreted as follows:

Interpreter: We should simplify procedures and take prompt action to import advanced technologies, and then organize workers to assimilate and popularize them. 
Sometimes, word-for-word interpretation of modifiers even causes doubts on the part of the listener and hinders conveyance of the intended message. For example, if “胜利召开” is rendered as “successfully convened", then the listener may assume that "the meeting must have gone through a lot of troubles before it finally convened." In the case of “热烈支持”, if it is literally interpreted as “earnestly support", the listener may wonder: "How can one's support not be earnest?" Therefore, the underlined modifiers in these two phrases should both be omitted in the interpretation.

\subsubsection{Transfer of Chinese Structure}

(3)

Chinese: 欢迎布朗博士来访上海。

Interpreter: Welcome you to Shanghai, Dr. Brown.

(4)

Chinese: 我们厂来了一位贵宾。

Interpreter: Our factory has a distinguished guest.

One reason for the transfer of Chinese structures is the neglect of the conventional usages of English expressions. In Example (3), the Chinese imperative structure “欢迎某人来访某地”, literally meaning “welcome somebody to somewhere", is a natural expression to the Chinese ears, but in English, rarely do people use such an imperative structure. Therefore, the interpretation "Welcome you to Shanghai, Dr. Brown." is a pragma-linguistic failure caused by the transfer of Chinese structure and should be instead interpreted as "Welcome to Shanghai, Dr. Brown."

Similarly, the interpretation "Our factory has a distinguished guest." in Example (4) is also an example of transfer of Chinese structure. To express the idea of existence, a Chinese sentence can begin with a locative phrase, as in the case of “我们厂来了一位贵宾。”, but an English sentence beginning with a locative phrase would be infelicitous, so a subject with an existential construction or an agent is preferred. Therefore, Example (4) is better interpreted as "There is a distinguished guest in our factory." or "A distinguished guest has come to our factory."

\subsubsection{Misuse of English Expression}

English: Thank you for your cooperation.

Interpreter: 非常感谢您的配合。

Chinese: 不用谢。

Interpreter: Never mind.

(6)

English: Which place do you like to visit first, the school or the factory?

Interpreter: 您想先参观学校还是先参观工厂呢?

Chinese: 都可以。

Interpreter: Whatever.

Pragma-linguistic failures also occur when interpreters fail to understand the implications of English expressions. In Example (5), "Never mind." is often used when someone has apologized to you and you have accepted the apology. It implies a consolation (He \& Yan, 1986). This differs from the implication of the source text --- to show politeness on the part of the listener. An appropriate interpretation here should be "You are welcome."

The expression “都可以。” is a typical answer given when a Chinese is asked to make a choice. Influenced by the Confucian philosophy of Doctrine of the Mean, Chinese people like to use fuzzy expressions as answers in order to show their politeness and prudence (Wang, 2002). The English expression "Whatever", on the contrary, is quite insulting. If someone visiting the U.S. asks a question or makes a statement and gets "Whatever" as a response, it means the person responding does not care what the speaker has to say. Therefore, the interpretation "Whatever" in Example (6) is also a pragma-linguistic failure and could be replaced by "Both will do." 


\subsubsection{Overuse of Full Sentence}

(7)

English: Another thing must be clear: any dispute of whatever nature arising out of or in any way

relating to the contract or to its construction or fulfillment may be referred to arbitration.

Interpreter: 还要明确一个问题: 凡有关本合同的制度和执行本合同所发生的任何争议都可

付诸仲裁解决吗?

Chinese: 当然, 所有争议都可通过仲裁解决。

Interpreter: Yes. Any dispute of whatever nature arising out of or in any way relating to the

contract or to its construction or fulfillment may be referred to arbitration.

(8)

English: Mr. Wu, have your confirmed your date of shipment?

Interpreter: 吴先生, 您是否已经确认了发货日期?

Chinese: 是的, 已经确认了。

Interpreter: Yes, I have confirmed my date of shipment.

It is not always necessary to use a full sentence in English. Sometimes, using a full sentence is at odds with the communication norms, giving rise to unintended implied meaning. According to Grice's Cooperative Principle (Grice, 1981), the maxim of quantity requires that no redundant information be given in communication, or else the listener may assume that the speaker has conversational implicature. In Examples (7) and (8), both interpretations have overused full sentences, which means that the interpreters have violated the maxim of quantity and misled the listeners to assume the conversational implicature that the speakers are a little impatient or annoyed. A good interpreter will simply say: "Yes, certainly." in Example (7) and "Yes, I have." in Example (8).

\subsection{Socio-pragmatic Failure in Interpretation}

Socio-pragmatic failures in interpretation refer to the inappropriate expressions used by interpreters due to a lack of knowledge of cultural differences. Causes and effects of socio-pragmatic failures in interpretation are examined as follows:

\subsubsection{Inappropriate Handling of Formulaic Speech}

(9)

Chinese: 最后, 我祝愿此次的“贸易论坛”取得圆满成功, 并祝与会代表身体健康, 家庭幸福。

Interpreter: Finally, I wish the "Trade Forum" a great success and wish you good health and a happy family.

Chinese has a set of conventional expressions that reflect the cultural traditions of the country and have pragmatic implications in specific contexts. These conventional expressions are called "formulaic speech" (Ran, 2006, p. 143). They are finely understood by the Chinese people, but may cause misunderstandings if interpreted literally into English. For example, the expression “家庭幸福” in Example (9) is often used at the end of an opening speech to show the speaker's good wish to the listeners. Its pragmatic implication of good wish is far more important than its literal meaning. However, this pragmatic meaning is missing in the English expression "a happy family", so the English listeners may find it funny or even off-topic to hear the speaker mention "family" on such a formal occasion. While interpreting this Chinese expression, the interpreter needs to make necessary amendments such as abridgement or adaptation in accordance with the skopos of the target text (Nord, 2001). "As long as these amendments are made based on the analysis of the source text and intend to keep the skopos intact, they can achieve positive effects unattainable by other methods of translation." (Chen, 2000, p. 11). Therefore, the expression can be interpreted as: "Finally, I wish the 'Trade Forum' a great success and wish you good health and a happy stay here." Look at another example:

English: Thank you for your help.

Interpreter: 谢谢你们的帮助。

Chinese: 这是我们应该做的。

Interpreter: That's what we should do. 
In Example (10), the expression “这是我们应该做的。” is traditionally used to show humbleness and politeness of a Chinese speaker, but the interpretation "That's what we should do." has turned this good intention of the Chinese speaker into thin air. Hearing this interpretation, listeners may assume that the speaker offered help because he/she did not have a choice. So, to get this good intention across to the listeners, the interpreter should bear in mind the cultural traditions of English-speaking countries and use such expressions as "With pleasure." or "It's my pleasure."

\subsubsection{Misinterpretation of Culturally-loaded Expression}

Chinese: 我们要在干部中继续开展“三个代表”重要思想的教育。

Interpreter: We need to continue education of our cadres in the important principle of "Three Represents".

“三个代表” in Example (11) is an expression with unique Chinese characteristics. It means that "The Communist Party of China represents the development trend of advanced productive forces, the orientation of advanced culture and the fundamental interests of the overwhelming majority of the people in China. However, the interpreter only uses "Three Represents", which makes almost no sense in English. As a result, when the expression “三个代表” appears for the first time, it should be handled with the technique of "explanatory translation/interpretation" (Duan, 1990, p. 7), which is the method of giving explanatory notes after the literal translation/interpretation of a culturally-loaded expression. A skilled interpreter then will interpret the sentence like this: We need to continue education of our cadres in the important principles of "Three Represents", which means that the Communist Party of China represents the development trend of advanced productive forces, the orientation of advanced culture and the fundamental interests of the overwhelming majority of the people in China. Look at another example:

Chinese: 我们的目标是发展成为行业的“龙头”企业。

Interpreter: Our goal is to develop the company into a "dragon-head" enterprise in the industry.

"Dragon" symbolizes nobility and good fortune in the Chinese culture, but in the western cultures it brings about an image of a scary monster with pointed teeth which often gushes fire. When hearing the expression " $a$ dragon-head enterprise", the English-speaking people will possibly think of brutality and evilness. It is difficult for them to associate it with superiority and high quality. In contrast, if it is interpreted as "a leading enterprise", no such misunderstanding shall arise.

\subsubsection{Misuse of Register for the Given Situation}

Chinese: 我们是商场的老朋友啦, 你就直接开个价吧。

Interpreter: We are good partners in trade. Could you possibly give us an offer?

Chinese: 在过去的两年里, 我们的合作非常愉快。

现在，你就拿些我们合资企业的产品让大家见识见识吧。

Interpreter: We have been cooperating very well over the past two years.

I wonder if you could show us some latest products of our joint-venture.

"The two parties involved in a communication activity should have a good knowledge of the effect of social factors (such as register) on the language used. A pragmatic failure arises if a person uses an inappropriate register for a given situation" (Chen \& Li, 2015, p. 10). In Examples (14) and (15), the speakers and listeners have been close business partners, so a rather informal register should suffice. But the interpreters used "Could you possibly...?" and "I wonder if you could..." respectively. These two very formal expressions may make the listeners in both situations wonder "Is my partner not satisfied with our partnership?" or "Why is my partner treating me as an outsider?" The misuse of register has led to pragmatic failures in both cases. Better versions are as follows:

(13) Interpreter: We are good partners in trade, so just give us an offer.

(14) Interpreter: We have been cooperating very well in the past two years.

Now, let's have a look at some of our latest products. 


\subsection{Malaprop-pragmatic Failure in Interpretation}

Liu and Zhong (2003) criticized Thomas's dichotomous classification of pragmatic failures as being too vague and lacking credibility. As a matter of fact, in interpretation practice, some pragmatic failures cannot be simply grouped into either pragma-linguistic failure or socio-pragmatic failure. They are correct in grammar and appropriate in context. They are caused not by the interpreter's neglect of linguistic differences or insensitivity to cultural variations, but by malapropism, i.e., a slip of tongue. According to Cambridge Advanced Learner's Dictionary, malapropism refers to the wrong use of one word instead of another word because they sound similar to each other. In this study, a pragmatic failure caused in this fashion is labeled a "malaprop-pragmatic failure". Look at the following example:

One morning, an interpreter is about to have her interpretation debut in an important business negotiation.

Chinese: 早上好, 布莱克先生。

Interpreter: Good afternoon, Mr. Blake.

Generally speaking, when someone says "Good morning" or "Good afternoon" to you, you are expected to respond with the same expression. In Example (15), however, the interpreter used "Good afternoon" when the speaker actually uttered a “早上好”which means "Good morning”. Though the interpretation is in conformity with English grammar and serves the same function of greeting, it is still a pragmatic failure and could be regarded as a slip of tongue caused by stage fright or high level of pressure on the interpreter's interpretation debut. Look at another example:

Chinese: 金秋十月，我们相聚广州，见证第120 届中国进出口商品交易会的开幕。

Interpreter: In this golden autumn month of October, we have gathered here in

Guangdong for the opening of the 120th session of the China Import and

\section{Export Commodities Fair.}

In Example (16), the interpreter was supposed to use "We have gathered here in Guangzhou...", but instead used "Guangdong" in the place of "Guangzhou". Guangzhou and Guangdong sound very similar, with the former being the capital city of the latter, a province in south China. Despite the interpreter's slip of tongue, the interpretation with the word "Guangdong" still reads correct and makes no change to the main idea (Note: Guangzhou, the capital city, is located in the center of Guangdong Province, so if you are in Guangzhou, you are in Guangdong, too). In this sense, the interpretation has achieved functional equivalence (Nida, 1993) with the source text. However, it fails to capture the pragmatic meaning and should be considered as another manifestation of malaprop-pragmatic failure.

\section{Development of Students' Pragmatic Competence in Interpreting}

From the analyses in the previous section, we have proved that pragmatic failures abound in interpretation and they come in three different categories. They affect the normal processing of interpreting activities. To solve the problem of pragmatic failure in interpretation, it is of great importance to develop interpreters' "pragmatic competence" (Thomas, 1983).

Pragmatic competence is the ability to comprehend and produce language appropriately in a communicative situation, taking into consideration the contextual elements necessary to derive implicit meaning (Kasper \& Kellerman, 1997). Pragmatic competence in interpreting, to be specific, refers to an interpreter's ability to understand verbal discourses with conventional and culturally-loaded expressions in a given language and to make appropriate amendments so as to produce a natural and spontaneous interpretation.

Today, it is a consensus in the interpretation circle that pragmatic competence in interpreting is an essential quality of an interpreter (Bao \& Qian, 2013). To develop interpreters' pragmatic competence, efforts should start with students enrolled in interpretation programs in colleges and universities. In this section, we will elaborate on the establishment of the "curriculum-textbook-teacher-teaching" scheme to develop students' pragmatic competence in interpreting.

\subsection{Optimizing Curriculum Setup}

According to National Criteria of Teaching Quality for BA Programs in China (hereafter shortened as NCTQBAQ), the specialty courses offered in interpretation programs in China are classified into three types: 
courses on language proficiency, courses on interpretation skills and courses on other relevant fields of study. Wang and Zhong (2017), by referring to the NCTQBAQ, concluded that language proficiency and interpretation skill courses have taken most of the class hours in the curriculum of college interpretation program, leaving very limited class hours for courses of the third type, such as Introduction to Linguistics, Intercultural Communications, etc. However, it is now widely recognized in the field of second language acquisition that "high levels of grammatical competence do not guarantee concomitant high levels of pragmatic competence" (Bardovi, 1999, p. 686). So greater attention should be paid to pragmatics-related courses. For instance, more varieties of pragmatics courses and more class hours should be offered. Once students have a good understanding of pragmatics, their pragmatic competence in interpreting will improve and pragmatic failures can be reduced or avoided.

\subsection{Compiling Pragmatics-oriented Textbooks}

Textbooks refer to teaching materials organized systematically and usually in a simplified manner for the purpose of learning (Zhang, 2001). Ideally speaking, interpretation textbooks are supposed to help students become skillful interpreters. Nevertheless, according to the survey conducted by Bao \& Qian (2013), out of the 21 interpretation textbooks available on the Chinese market, most center on interpretation skills and strategies, often supplemented with exercises. Little introduction is given to the inter-relationships between pragmatics and interpretation, which partly explains why pragmatic failures often occur in interpretation. To change the status quo, it is proposed here that future interpretation textbooks give a heavier weighting to pragmatics-related contents. For example, there can be an individual section dealing with interpretation from the perspective of pragmatics, such as interpretation and Cooperative Principle, interpretation and Politeness Principle, and so on.

\subsection{Updating Teachers' Mindset}

Teachers are both designers and practitioners of teaching activities. They are one of the most important factors affecting the quality of teaching. In order to develop students' pragmatic competence in interpreting, teachers must abandon the traditional mindset that language proficiency and interpretation skills are the center of interpretation teaching. Meanwhile, they should develop their own pragmatic awareness. If teachers have low pragmatic awareness, chances are dim that they will emphasize the learning of pragmatic knowledge in interpretation training, and it is meaningless talking about developing students' pragmatic competence in interpreting.

\subsection{Diversifying Teaching Methods}

To develop students' pragmatic competence in interpreting, in addition to traditional teaching methods such as teachers' lecturing and individual interpretation skill drilling, efforts should be made to shape a "learner-oriented" teaching atmosphere in which students take initiatives to interpret in authentic classroom simulations. If conditions permit, students should be provided with opportunities to engage in real-life interpretation activities. "Classroom simulations must be made as close as possible to real-life situations, and teaching materials must be authentic" (Chen et al., 2010, p. 28). Moreover, due to linguistic and cultural differences, particular training should be given to such items as formulaic speech, idioms and proverbs, culturally-loaded expressions, etc. It is also worth noting that pressure training should be offered to students in order to help them avoid malaprop-pragmatic failures caused by pressure or stage fright.

\section{Conclusion}

The education of interpretation lies not only in the cultivation of students' language proficiency and interpretation skills, but also in the development of students' pragmatic competence. In fact, good pragmatic competence is one of the qualities found in successful interpreters.

To sum up, this study has proposed a trident classification model based on Jenny Thomas's dichotomous classification in an attempt to better explain pragmatic failures in interpretation. In the meantime, the present study also establishes the "curriculum-textbook-teacher-teaching" scheme to develop students' pragmatic competence. This is based on the belief that students who have good pragmatic competence in interpreting will be alert to the fine shades of differences between languages and cultures, and can ultimately avoid pragmatic failures in interpretation.

\section{Acknowledgments}

This study is funded by the 2018 Research Innovation Team "Pragmatic Culture and Identity Construction" of Guangdong University of Foreign Studies, China. 


\section{References}

Bao, X. Y., \& Qian, M. D. (2013). A model for enhancing students' pragmatic competence in interpreting. Foreign Language World, 1, 88-94.

Bardovi, H. K. (1999). Exploring the interlanguage of Interlanguage Pragmatics: A research agenda for acquisitional pragmatics. Language Learning, 49(4), 677-713. https://doi.org/10.1111/0023-8333.00105

Chen, L., Tan, J., \& Xiong, W. (2010). A probe into question-driven teaching based on Constructivism. Forum on Contemporary Education, 9, 27-29.

Chen, X. R., \& Li, M. (2015). A study of pragmatic failure in the ELF context. Foreign Languages and Their Teaching, 2, 7-12.

Chen, X. W. (2000). Implications from functionalist concept of translation: New ideas on some translation methods. Chinese Translators Journal, 4, 9-12.

Cruz, M. P. (2013). Understanding and overcoming pragmatic failure in intercultural communication: From focus on speakers to focus on hearers. International Review of Applied Linguistics, 51, 23-54.

Duan, L. C. (1990). Call for attention to translation of publicity materials. Chinese Translators Journal, 5, 2-10.

Economidou-Kogetsidis, M. (2011). Please answer me as soon as possible: Pragmatic failure in non-native speakers' e-mail requests to faculty. Journal of Pragmatics, 13, 3193-3215. https://doi.org/10.1016/ j.pragma.2011.06.006

Ellis, R. (1992). Learning to communicate in the classroom: A study of two language learners'request. Studies in Second Language Acquisition, 14, 1-23. https://doi.org/10.1017/S0272263100010445

Grice, H. P. (1981) Presupposition and conversational implicature. In P. Cole (Ed.), Radical pragmatics (pp. 269-282). New York, NY: Academic Press.

Hao, Q. H. (2000). Cross-cultural pragmatic failure in advertising language: A study of the language in English advertisements translated from Chinese. Foreign Language Education, 7, 26-31.

He, Z. R., \& Yan, Z. (1986). Chinese students' pragmatic failures in English communications: A survey on pragmatic differences between Chinese and English. Foreign Language Teaching and Research, 3, 52-57.

Kasper, G., \& Kellerman, E. (1997). Introduction: Approaches to communication strategies. In G. Kasper, \& E. Kellerman (Eds.), Communication Strategies: Psycholinguistic and Sociolinguistic Perspectives (pp. 1-13). London, England: Longman Publishers.

Liu, C. J. (2008). Interpretation and critique on Thomas's theory on cross-cultural pragmatic failure. Foreign Languages Research, 6, 36-39.

Liu, S. Y., \& Zhong, G. S. (2003). Thomas's dichotomous classification of pragmatic failure revisited. Journal of Guangxi Normal University, 4, 47-50.

Nida, E. A. (1993). Language, Culture and Translating. Shanghai, China: Shanghai Foreign Language Education Press.

Nord, C. (2001). Translating as a purposeful activity: Functionalist approaches explained. Shanghai, China: Shanghai Foreign Language Education Press

Pöchhacker, F. (2016). Introducing Interpreting Studies (2nd ed.). London, England: Routledge https://doi.org/ $10.4324 / 9781315649573$

Ran, Y. P. (2006). Pragmatics: Phenomenon and its analyses. Beijing, China: Peking University Press.

Setton, R. (1999). Simultaneous Interpretation: A cognitive-pragmatic analysis. Amsterdam and Philadelphia, Netherlands and United States: John Benjamins Publishing Company. https://doi.org/10.1075/btl.28

Sun, Y., \& Dai, L. (2002). A survey of pragmatic failure study in China. Foreign Languages and Their Teaching, $3,19-21$.

Thomas, J. (1983). Cross-cultural pragmatic failure. Applied Linguistics, 4(2), 91-112. https://doi.org/10.1093/ applin/4.2.91

Wang, J. (2007). Cross-cultural pragmatic failure: Causes and solutions. Heilongjiang Research on Higher Education, 9, 176-177.

Wang, T. (2002). On cross-cultural pragmatic failure in interpretation. Chinese Science \& Technology 
Translators Journal, 1, 19-21.

Wang, W. W., \& Zhong, W. H. (2017). Curriculum reform and development for English programs in light of National Criteria of Teaching Quality for BA Programs. Foreign Language World, 3, 2-8.

Zhang, M. F. (2001). English-Chinese Translation Textbooks in China (1994-1998). Shanghai, China: Shanghai Foreign Language Education Press.

\section{Copyrights}

Copyright for this article is retained by the author(s), with first publication rights granted to the journal.

This is an open-access article distributed under the terms and conditions of the Creative Commons Attribution license (http://creativecommons.org/licenses/by/4.0/). 